\title{
FLOWPATH EVALUATION AND RECONNAISANCE BY REMOTE FIELD EDDY CURRENT TESTING
}

by

A. E. Smoak

Westinghouse Savannah River Company

Savannah River Site

Aiken, South Carolina 29808

W. T. Zollinger

This paper was prepared in connection with work done under the above contract number with the U.S. Department of Energy. By acceptance of this paper, the publisher and/or recipient acknowledges the U.S. Government's right to retain a nonexclusive, royalty-free license in and to any copyright covering this paper, along with the right to reproduce and to authorize others to reproduce all or part of the copyrighted paper. 


\section{DISCLAIMER}

This report was prepared as an account of work sponsored by an agency of the United States Government. Neither the United States Government nor any agency thereof, nor any of their employees. makes any warranty, express or implied, or assumes any legal liability or responsibility for the accuracy, completeness, or usefulness of any information, apparatus, product, or process disclosed, or represents that its use would not infringe privately owned rights. Reference herein to any specific commercial product, process, or service by trade name, trademark, manufacturer, or otherwise does not necessarily constitute or imply its -ndorsement, recommendation, or favoring by the United States Government or any agency thereof. The views and opinions of authors expressed herein do not necessarily state or reflect those of the United States -Government or any agency thereof.

This report has been reproduced directly from the best available copy.

Available to DOE and DOE contractors from the Office of Scientific and Technical Information. P. O. Box 62, Oak Ridge. TN 37831; prices available from (615) $576-8401$.

Available to the public from the National Technical Information Service. U. S. Deparment of Commerce, 5285 Port Royal Rd., Springfield, VA 22161 


\section{Elowpath Evaluation and Reconnaisance by Remote-field Eddy current Testing (FERRET)}

THE VISION: STORE NUCLEAR WASTE SAFELY.

THE MISSION: CARRY AWAY EXCESS HEAT.

THE METHOD: PIPE COOL WATER THROUGH THE WASTE.

THE PROBLEM:HOW TO INSPECT THE COOLING PIPES??

If you put the tips of your thumb and middle finger together, you'll make a circle about two inches in diameter, the width of the steel pipes which carry cooling water to the vast underground storage tanks where nuclear waste is stored. Two inches - that's not much room to maneuver. But WSRC equipment engineers have invented a remarkable new method to safely examine those pipes, pinpointing any damage or leaks that may exist.

The system is named for the ferret, a slender mammal whose willing personality and deep curiosity have endeared it for centuries to hunters of moles, rats and rabbits. Ferrets are so good at invading tunnels that their name has become a verb, meaning "to uncover and bring to light by searching."

The story of our FMRRIS is one of dedication, perseverance, imagination, and teamwork, and our engineering team's success reflects Westinghouse Savannah River Company's committment to safety, quality and overall excellence. 


\section{COOLING PIPE INSPECTION - THE WAY IT WAS}

For four decades, the Savannah River Site has used Underground Storage Tanks (UST's) to store the high level radioactive waste products produced by the site's processes. As high level waste decays, the heat it generates can build up in the tank due to the insulating effect of the surrounding earth. To remove the heat, a cooling system was built into the UST's.

But limited access to the tank's interior, meant to shield workers from exposure to radiation, has made inspection of the cooling system difficult. If losses of cooling fluid occur through cracks and leaks in the cooling pipes, engineers have little or no access to the pipes, so the causes of leaks, the "mechanisms of failure", cannot be truly determined.

\section{Complex pipe geometry}

Each UST cooling system has twenty-three internally suspended pipe loops formed of two inch diameter welded carbon steel pipe. Since all the loops begin and end at common headers on the tank top, several 90 degree bends, called elbows, are found in each loop. This arrangement allows leaky pipes to be isolated without losing cooling power in the rest of the loops. Each UST requires four miles of loops to position a vertical pipe every three feet throughout the waste, but each loop may also have up to thirty 180 degree bends. See figure 1.
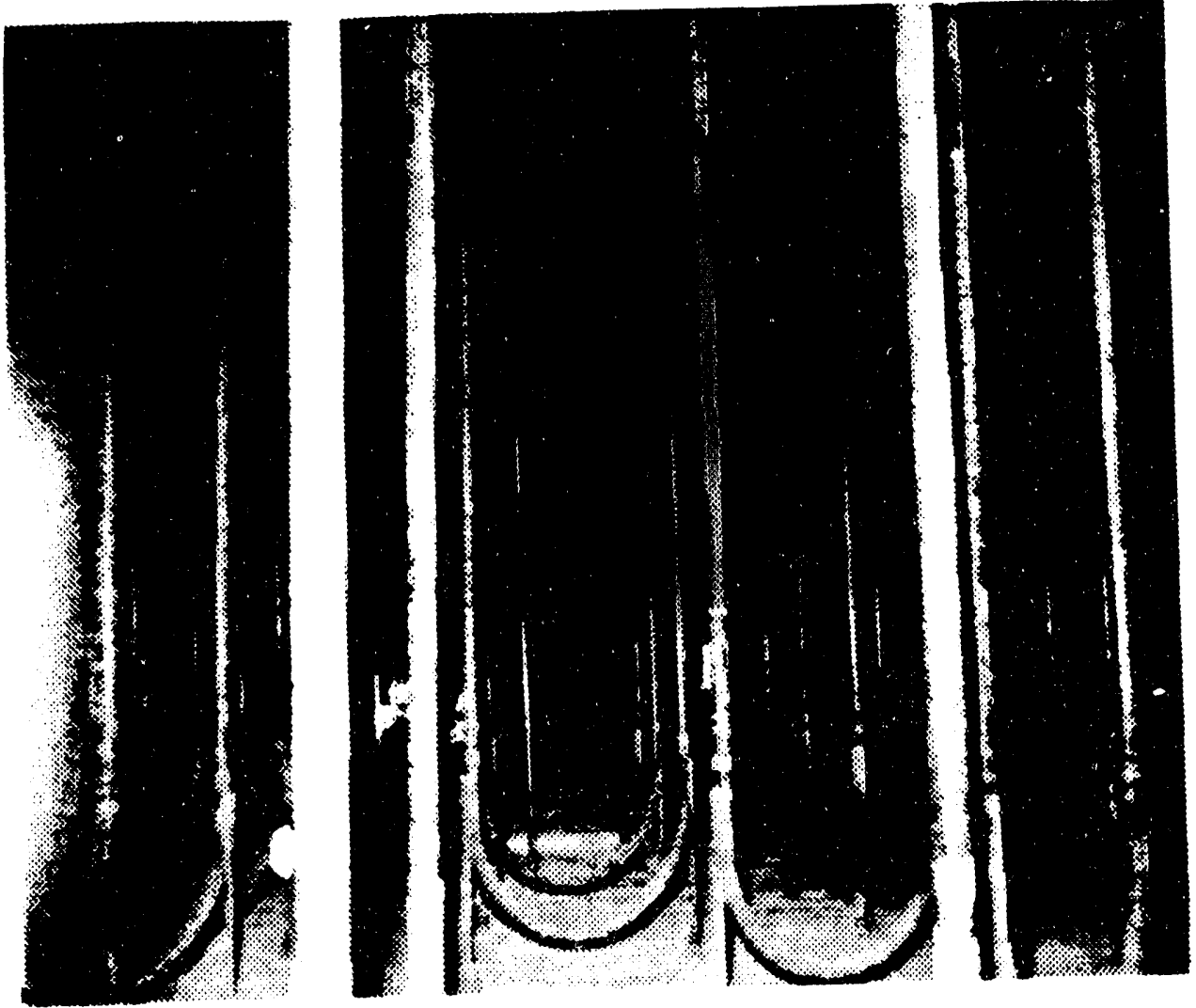

Figure 1 - Cooling plpos inside a high lovel waste tank 
Any cooling system inspection technique must also include pipe lengths embedded in the waste and in the four foot-thick concrete of the tank top. The only access to these pipe sections is from inside the pipe, where the small pipe diameter and the many bends and elbows severely limit access to corroded or damaged sections.

To address this problem, WSRC's Equipment Engineering Section proposed a new inspection system that could deliver an ultra-flexible remote field inspection device into the cooling pipes. The proposed device, a miniature, batterypowered eddy current probe, is hydraulically propelled through each cooling pipe by an external pump. It sends its data signals back to the launch point along slender trailing wires, freely passing through the maze of loops and elbows, unlike tethered probes, which often get stuck due to cable friction.

Commercial Pipe Inspection Systems Inadequate Small pipe inspection equipment from over 65 vendors was reviewed, and most of it was not able to pass through more than four elbows. Many of these probes were pushed or pulled through the pipe on thick signal cables. A few systems were wireless, but designed for pipes four inches or greater in diameter, with very long radius elbows. The reviewers also found no commercial equipment that was modifiable to match the configuration of the cooling pipes, and they determined that custom equipment was needed to inspect the UST cooling systems.

\section{EQUIPMENT DEVELOPMENT PROGRAM}

\section{Small Scale Cooling Pipe Mock-up}

The small scale mock-up was built to evaluate the mechanical behavior of the early probe designs within a clear piping system, troubleshoot motor control design, and prototype launching system concepts. Straight sections of clear PVC pipe were joined to short radius carbon ste日l elbows and mounted on a cart, along with a positive displacement pump and a computer control system, comprising a mobile testing and displav platform. After a few design changes, a launch tube section was added, and this pruiotype has since been used for DOE demonstrations and technology transter activities.

Improved Full Scale Mock-up

To ensure test accuracy, a full scale mock-up was constructed to the material and welding specifications for UST cooling pipes. Pipe openings were flanged, for easy attachment of the launching device, and three loops of a typical cooling system were fashioned, with their 90 degree elbows embedded in concrete at the point where they would normally enter the tank. A removable, deliberately flawed pipe section was added to test the probe's diagnostic power, and various leaks of different diameters were drilled through a vertical section of the pipe, for testing pressure leak sensors. 


\section{Flaw Detection Experiments}

Several pipe standards with machined flaws of different depths, lengths, types, and orientations were made to verify the probe's accuracy in bench top tests. These flaws included: axial and radial cracks of $25 \%$ to $75 \%$ through-wall, pits varying from $25 \%$ to $75 \%$ through wall. and wall thinning from $25 \%$ to $75 \%$ through wall.

\section{Early FBRRET prototypes}

Several eddy current probes were designed, all featuring a single driver coil with varying pick-up coil patterns, mounted on a threaded bar armature,for easy adjustment of the gap between the coils. Initial tests were made with both absolute (figure 2) and differential (figure 3) pick-up coil schemes.

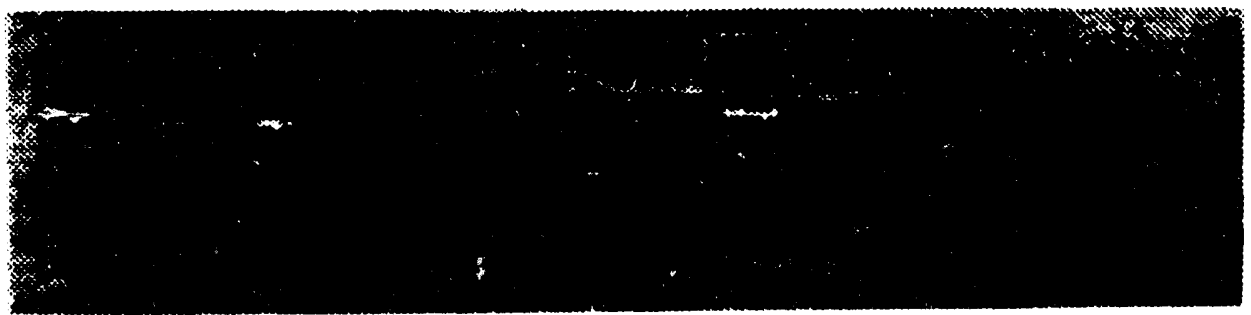

Figure 2 - Remole finld eddy cunent probe with absolute plek-up coll

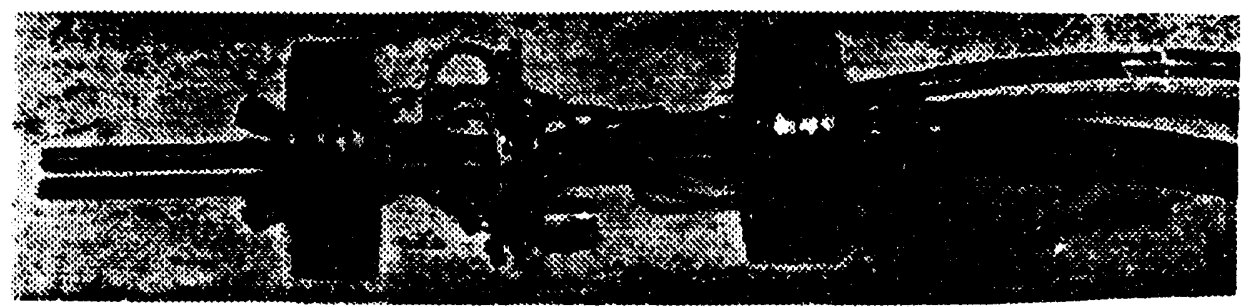

Figure 3 - Remote fiold ecidy current probo with difforential pick-up colls

As testing progressed, four channel differential pancake coils and radial edge coils were tried. Both schemes increased the probe's sensitivity to pits, but the radial edge coil (figure 4) gave better circumferential coverage of the pipe wall. 


\section{Developing the FERRET launcher}

The launcher inserts, moves, and retrieves probes from a piping system while minimizing personnel exposure to hazardous or contaminated fluids. Inspection probes are move along with the working fluid (water in this case) which is propelled by a gear driven pump. By operating in a closed loop, precise fluid and probe movement can be achieved in both directions.

\section{Field Conditions}

The UST cooling pipes are accessed from the tank top, where a valve house encloses the main headers supplying coolant to the 23 loops descending into the tank. The supply and return lines from the loops are valved so that sections of the system can be isolated from the main headers. A single loop is isolated by removing one supply valve and its partner return valve, and closing off the headers. Located at three different elevations on the supply side and two elevations on the retum side, the valve geometry greatly complicates the connection piping needed $:$. inspect en er.tira tank.

Access to the valve house is through a narrow doorway. All connection piping sections and launcher equipment must fit through this doorway and within the narrow aisle inside the valve house.

The cooling water, treated with chromate to inhibit corrosion, is radioactive, so all fluid used in, or drained or vented from the launching system and connectors is contaminated and must be contained. Furthermore, the radiation field from the waste itself requires workers to minimize time spent on the tank top. Thus the installation of connection piping had to be simplified, and launcher operations had to be conducted remotely whenever possible.

\section{Prototype Launcher Design}

The prototype launching system was built to accommodate design changes by making each leg of piping in the launcher accessible. The frame was designed with long piping to allow added pressure taps, vent lines, etc., and was built from heavy gauge steel to support any heavy equipment that may be added. A field launcher would be much smaller and lighter than the prototype. See figure 5. An elbow and connecting pipe must be installed to connect the launcher to a cooling pipe. A gear pump, centrally located in the launcher frame, propels the probe through the pipe in a closed loop. This type of pump was chosen to eliminate pressure pulses. To minimize contamination, all legs of the launcher are set up for easy draining, and all vents and drains are captured. The launch tubes are vertical, to limit spillage during insertion and retrieval of probes, and oversized, for easy device insertion and removal. The probe vehicle's pointed nose and tail sections and the four flexible seals along its length gravity-feed the vehicle into the pipe. The thi"e日 inch diameter launch tubes taper sharply to two inches at the base,allow entering probes to fit loosely, and exiting probes to be easily retrieved from the two incin pipe. 


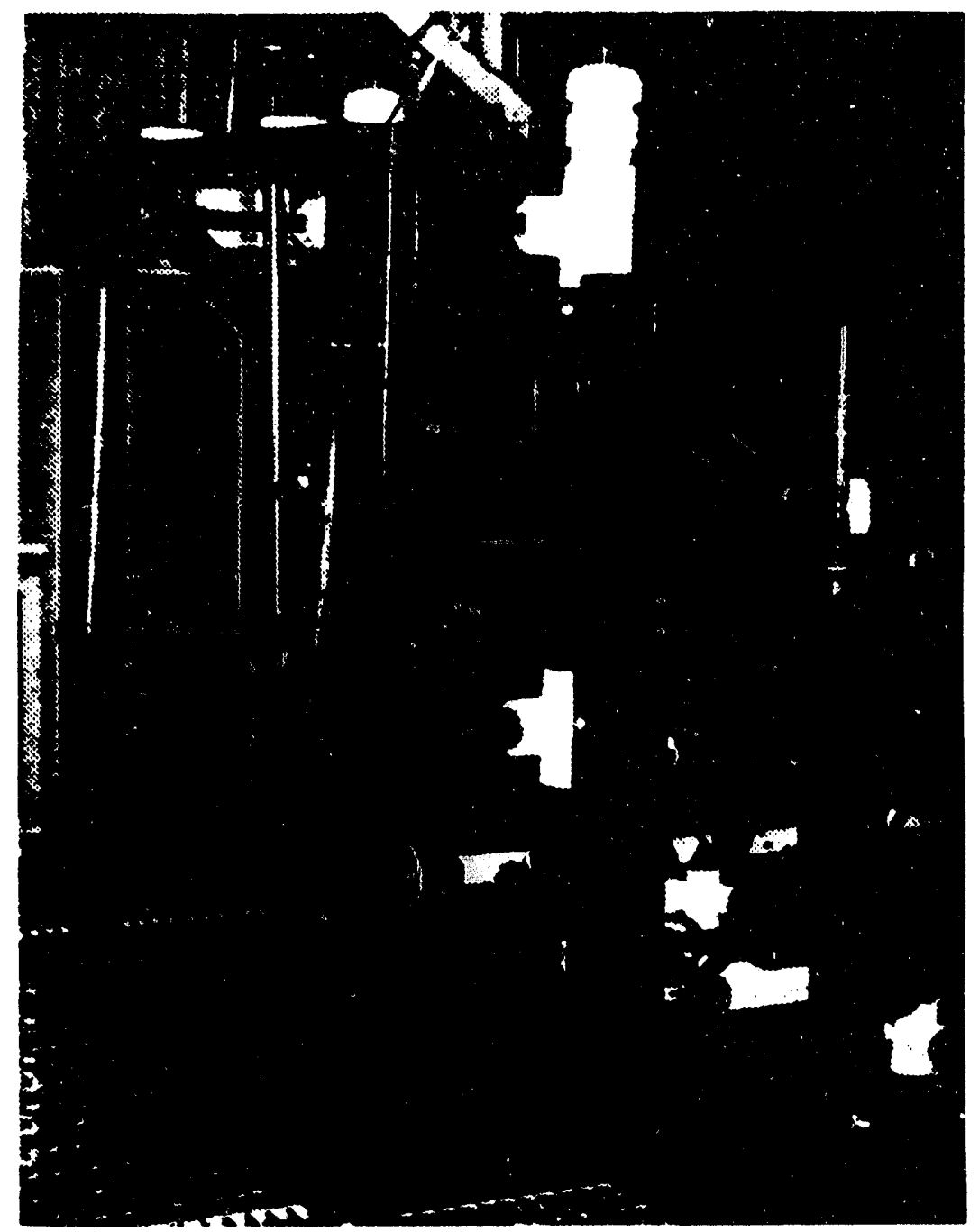

Figure 5 - FEIIIT Prototypo Launchor Systom

The straight sections of two and three inch tubing in the small launcher prototype are made of clear PVC, allowing the operators to monitor water levels within the launcher and observe the position of inspection devices. In addition, air bubbles can be monitored during venting operations as the piping is cleared of air pockets. Air removal is important for smooth vehicle motion, so the ventlines are also of clear tubing to let operators see whether all air has been purged from the launch tubes. The launcher prototype enables many flow path options. It allows open loop and closed loop testing, and pressurization of the suction or discharge lines. These options are valuable for testing the dynamics of device movement through piping systems and helped in optimizing the system.

Proposed field ready design

The current prototype is the culmination of many design iterations. Pumping many probes through a UST cooling system mock up and evaluating the results proved the design's viability, and showed the inherent flexibility of the system. A field ready design would function like the prototype launcher, except the frame's size and weight will be drastically reduced for portability. The piping size will also be reduced, but will keep all the features of the current prototype. Other changes include adding solenoid operated valves for remote operation, and video equipment for monitoring. 
A compact launcher for routine pressure testing Because ordinary cooling pipe pressure inspections are performed with small inserts called pigs, a twelve inch tube would suffice for launching the cleaning pigs. Therefore, a compact probe launcher design, which would be built without full length (over six feet) launch tubes, is being considered for performing pressure inspections. The pressure inspection launcher will be designed so that it can be modified to support testing using the eddy current probe. The shorter tube lengths will lower the amount of test-generated contaminated waste.

\section{FERRET development}

The geometry of the cooling system pipes requires a probe which can successfully negotiate over 30 elbows, some of them short radius. This fact inspired the development of a new propulsion technique, and flexible vehicle capable of passing through short radius elbows without the hindrance of a large cable.

\section{Structural constraints}

The most basic constraint upon this probe vehicle is that it must move inside a water-filled pipe two inches in diameter. Another limiting constraint is that the vehicle must be able to negotiate up to thirty $180^{\circ}$ and $90^{\circ}$ bends in the pipe. The most obvious means of moving an independent vehicle within a water-filled pipe is to push it with water. A flexible seal was devised which allowed water pressure to push a vehicle along a straight section of pipe. The seal consisted of a circular disk of rubber mounted within a solid silicone test vehicle.

Most commercial inspection devices use a large cable for moving the probes, and transmitting information out of the pipe, but the force needed for moving a cable through a pipe increases exponentially with each elbow. After passing through just three elbows, a tethered system is immobilized. To eliminate the bulky cable, an alternate communications scheme was developed using very fine twisted pair wire. However, the fine wire would not accommodate data from the multiple probes. This required that the vehicle contain most of the circuitry for the detection instrumentation.

\section{Early vehicle designs}

The first vehicle concepts were combinations of hard mechanical sections and mechanical links. These designs were inefficient containers for the internal components, and tended to get stuck when the links articulated at odd angles. There was no simple method for running wires between the sections, or for housing circuit cards, but the circular disk seals from these early models worked well in straight sections of piping. A better idea was needed. 


\section{Pliable prototypes}

The first pliable prototype was made from solid silicone rubber. It had a pointed nose and tail section with body segments separated by urethane rubber disk seals. The silicone, allowed to flow through the center of the seals to hold the vehicle together, did not cure as expected, forming large gas pockets. A two part silicone was used to correct this problem. See figure 6.

The pliable vehicle could negotiate the elbows, but did not move smoothly due to the high friction of the silicone. This problem was overcome partially by sheathing the vehicle in Teflon ${ }^{T M}$ shrink tubing, which had to be slitted to allow bending around corners. The edges of the slits were found to be catching on rough welds in the full scale mock-up, and the molded body did not allow for troubleshooting or replacement of components after assembly.

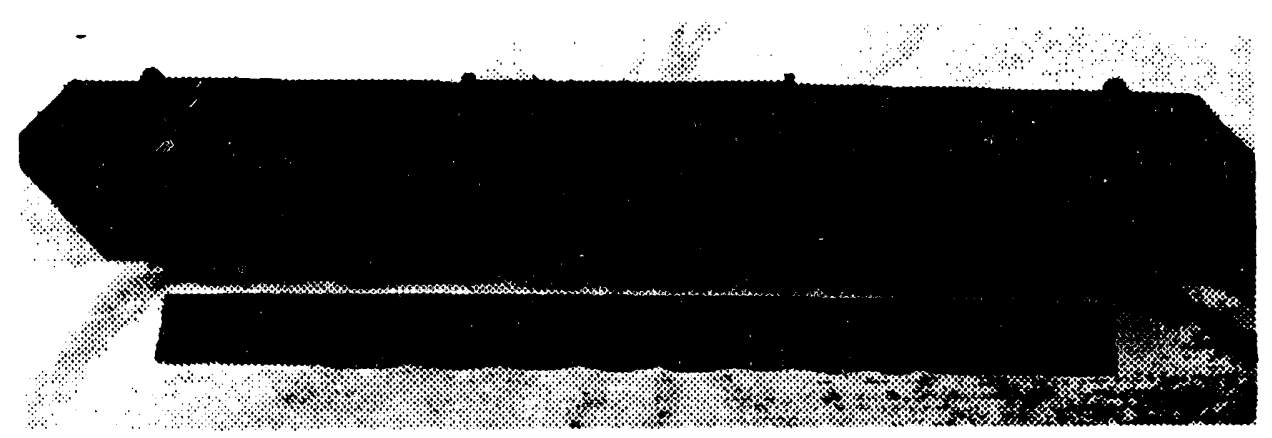

Figure 6 - Solld sllicone Fith

Concurrent with the shrink tubing test, an second molded-silicone vehicle was prototyped, this time with an alternate seal style. The seal was molded as a raised band around the silicone body of the vehicle. See figure 7 . This design would have produced a more durable molded vehicle by removing the weak point wt are the silicone passes through the disk seal, and would have shortened the vehicle, but in testing, the molded seal was not compliant enough to pass over weld crowns. The friction would jam the vehicle, compressing the body and locking the vehicle in place by the expansion of the silicone as it compressed.

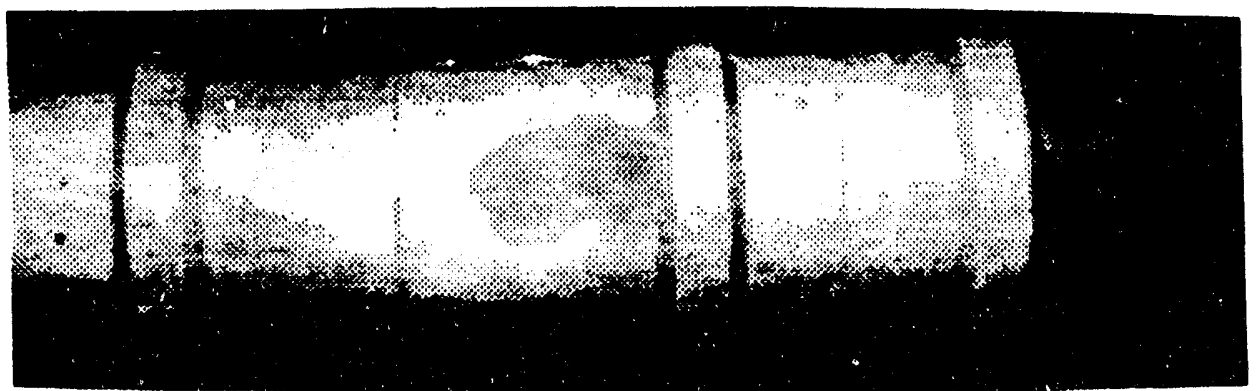

Floure 7 - Molded vohicle with ralsed allicone bands 
To eliminate the friction problem and allow for disassembly, another version was developed using corrugated tubing for the body of the vehicle. The nose, tail, and joints were made from Delrin ${ }^{\mathrm{TM}}$ (a slick plastic), and a steel clamp was used to connect the tubing to the plastic sections. See figure 8. During testing, the nose and tail sections caught on weld crowns going through elbows, causing the body to compress. The deformation would halt all forward motion and destroy components in the vehicle.

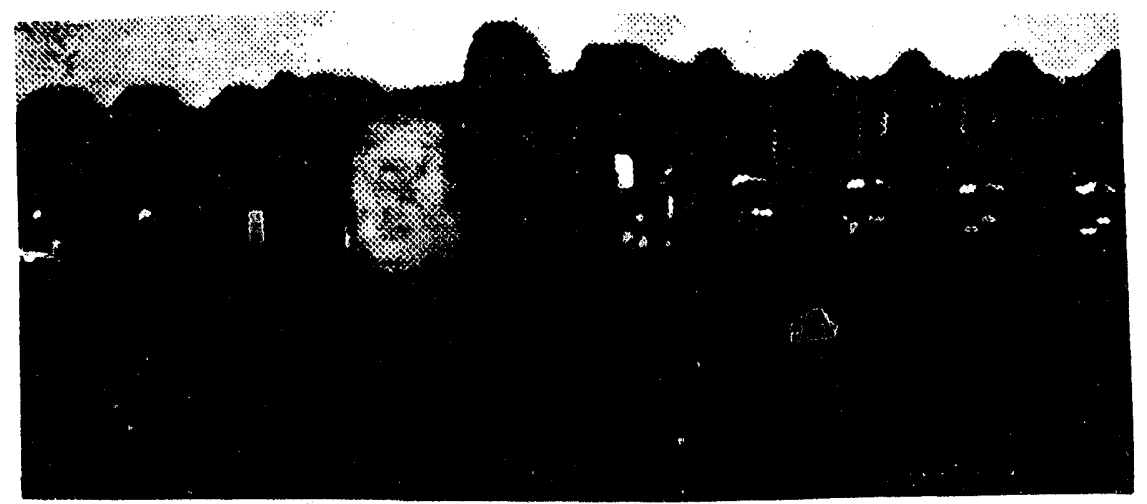

Figure 8 - Comsolted body with segments folned to Dolith in sections

The birth of an agile "FWing

New nose and tail sections of various materials and shapes were designed and tested, and an alternate assembly technique was attempted. Pieces were made from PVC and glued directly to PVC tubing. None of the new configurations negotiated the weld crowns at elbows as effectivelyas the first silicone rubber prototype, but the glued assembly method worked extremely well. Varying thicknesses of disk seals, clamped between the Deirin ${ }^{\top M}$ pieces, were also tried. The seals tended to fold over, neutralizing the hydraulic pressure that moved the probe. Adding more thickness to stiffen the seals resulted in the seals catching on the weld crowns. A new hybrid design was developed using the best features of the first silicone rubber vehicle and the later corrugated tubing version. See figure 9. The silicone vehicle's soft nose and tail were used, as was the disk seal molded into the rubber, which allowed the seals to fold back when clearing weld crowns. The rubber also supported the seal front and back, allowing use of a thinner disk without reintroducing the blow by problem. The best features of the corrugated tubing version were its low friction outer surface and its ease of assembly and repair using the gluing technique. The only problem in merging the two designs was connecting the silicone sections to the PVC tubing. A unique joint was designed in which the silicone is molded through a PVC connector, which in turn could be glued to the PVC tubing. This streamlined troubleshooting and repair, since now it was very casy to cut away the tubing to work on components and reassemble the vehicle in a new piece of tubing. 


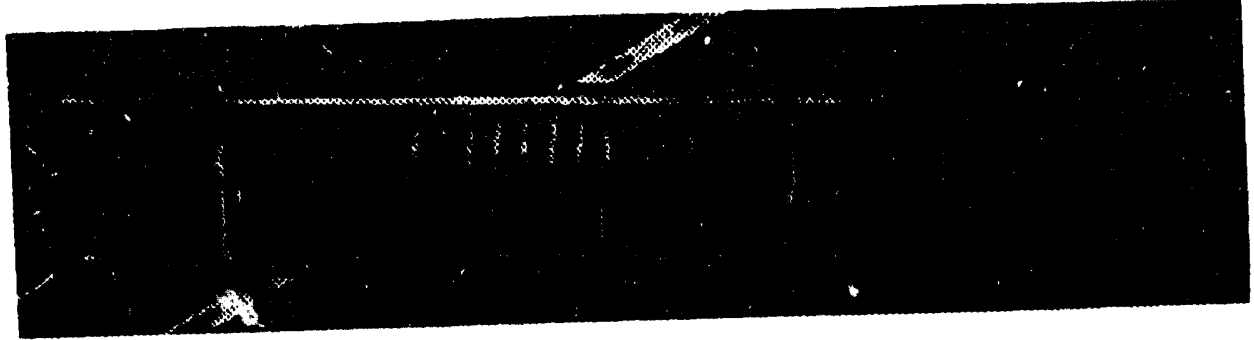

Flgure 9 - Hybrid deslgn uaing allkcone secilons and corrugated body

An improved joint was designed so that the communications wire spool could be changed without regluing. The new joint, built around a piece of plastic tubing and tubing quick-connects, allows the joint to be disconnected so the spool section can be changed, and the vehicle reinserted into the pipe to continue the inspection. The current hybrid model performs flawlessly, scooting through the large mockup at pressures of about 8 psi for straight sections and peaks of 15 psi through the elbows. The vehicle has traveled through over a mile of tubing and through hundreds of short radius $90^{\circ}$ elbows with no failures.

\section{Innovative electronics packaging}

Those $90^{\circ}$ elbows in the cooling pipe flow path proved to be the biggest

challenge to printed circuit board (PCB) design. Because of the flexible vehicle, the design of the PCBs and components had to be evaluated as three dimensional objects, so computer models of the vehicle were generated to determine the optimum PCB configurations. Several shapes were considered, including: circular, rectangular, oval, ... even flexible. The computer model showed that the circular and oval designs had the best chances of success. The circular design was built and tested first, but it didn't have enough space for the electronic components, and it complicated the task of managing wires which bridged neighboring circuit boards. The oval design solved the space problem by nearly doubling the surface area, and two of them, placed back to back, provided an elegant solution to the bridging obstacle. 


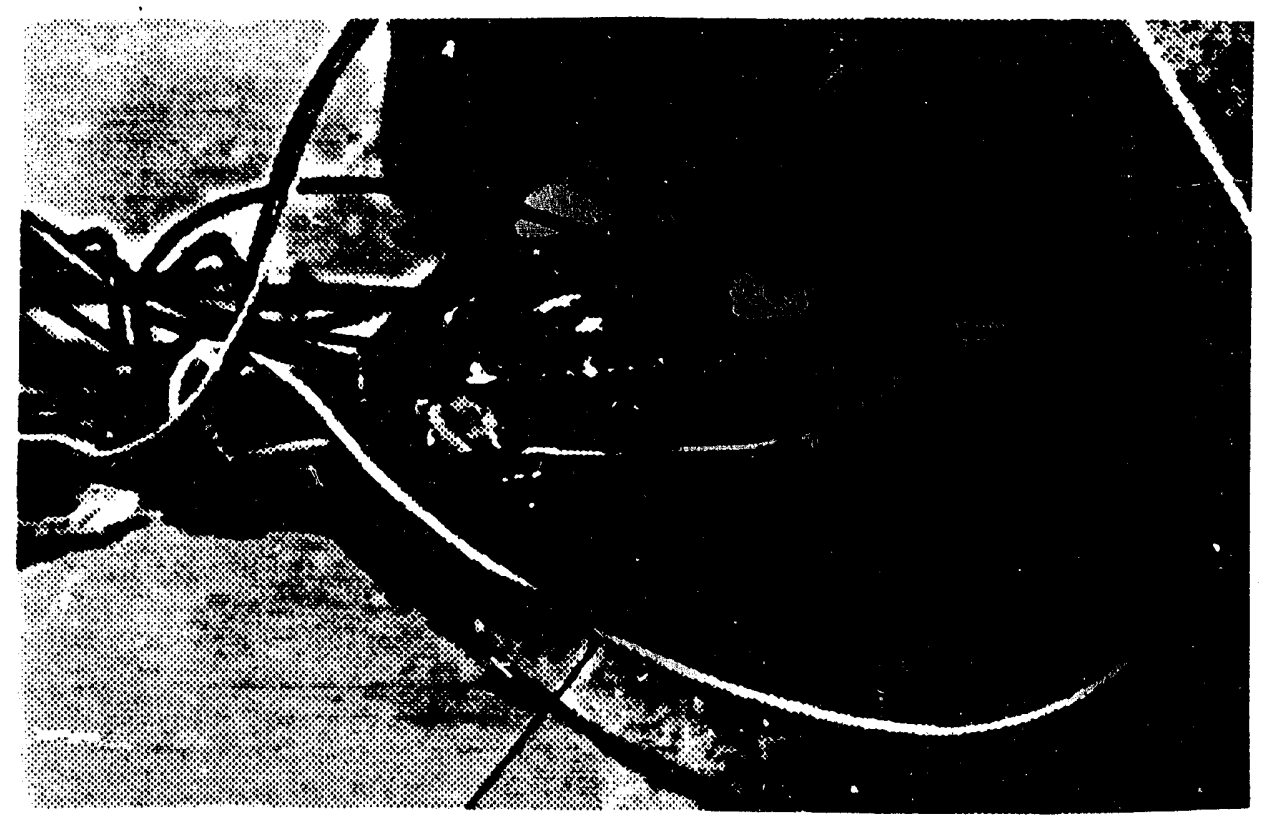

Floure 10 - Oval shaped prinied circult bocrds with connection wires

Waterproofing was the next design challenge. Of the many potting compounds that were tried, silicones were generally too soft, and did not adhere well. Urethanes adhered to the PCBs and components, but would liquefy as the electronics heated up. Epoxies worked, but were difficult to manage during assembly. Finally, electrical resins proved to be the best option. They were easy to pour into the molds, adhered well, and allowed access for repair.

During electronic component testing, the tiny pickup coil wires were always breaking, so a PCB was placod between the coil sets to act as a strain relief for the wires, which were potted in epoxy to the board. Another problem was shortcircuiting on the boards as they flexed under compression from the vehicle. A spine of heavy gage metal wire, placed along the centerline of the PCBs and batteries, prevented this from recurring.

\section{Planned physical improvements}

An external power connector could be added, to extend the amount of time the vehicle can sit idle in the launch tube, . By placing a disconnect in the tail of the FHRRET, the power connections could be maintained indefinitely while it is in the launch tube. The circuitry for the battery pack is set up to maintain charging with the FWRRDT circuitry off while power is applied. This will be neccessary to minimize personnel exposure when the rabbits begin inspection of contaminated cooling coils. No other improvements to the vehicle are necessary at this time. 


\section{Principles of eddy current technology}

Eddy currents are the currents that exist on the surface of conductive materials when excited by an external energy source. Usually, the external source is a coil, through which alternating current $(A C)$ is passed. Near the surface of nonferrous conducting metals, such a source creates secondary electric currents on the surface of the metal which eddy, or move opposite, to the direction of the inductive current. Figure 11 demonstrates this phenomenon.

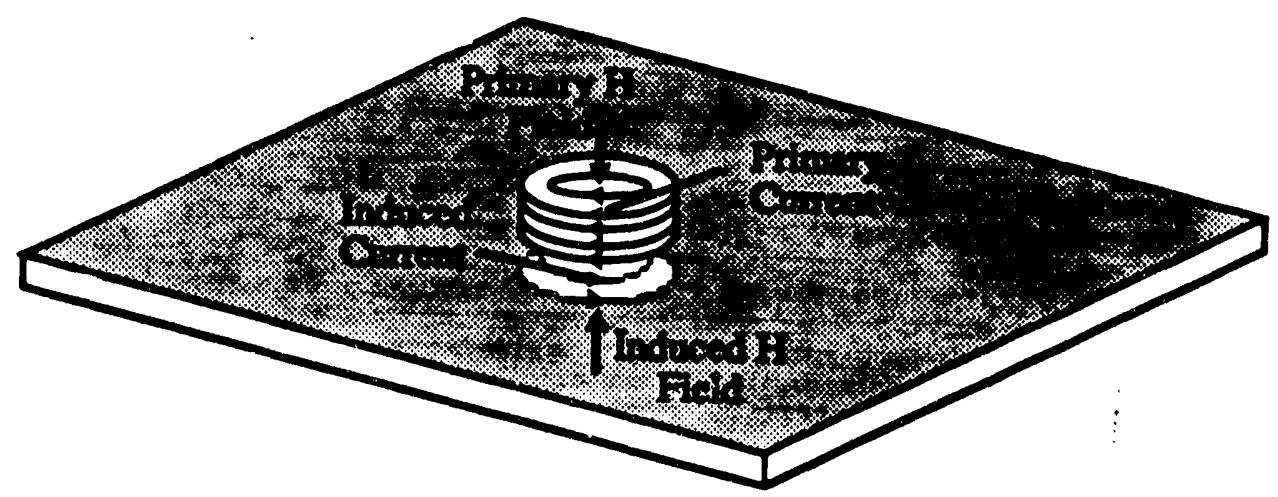

Figure 11 - Eddy current rosulting from coll noes nonforrous conductive surfoce

A decrease in inductance occurs, and resistance values increase as the coil nears the conductive surface due to the opposing magnetic fields. When the design of the eddy current probe keeps a constant distance between the coil and the surface, any variations in the coil's impedance must be due to variations in the conductive surface. Even tiny flaws in materials will register such changes. However, the UST cooling pipes are made of steel, which behaves differently under conventional eddy current testing. In ferrous metal, the inductance of the coil will increase as the coil nears the conductive surface. Also, the magnetic field, unless generated at extremely low frequencies, fails to fully penetrate the material, reducing the sensitivity of the eddy current coil to outside wall thinning, pits, and cracks. And since low frequency operation would lower the probe's average travel speed, conventional eddy current is not practical for inspecting ferrous materials. Other techniques had to be identified.

Remote field eddy current (RFEC) probes like FDi IRIT use two coils, separated by about three times the diameter of the pipe being tested. This inspection method improves the probe's ability to detect flaws on the outer surface of the pipe. Figure 12 shows the two energy-coupling paths between the driver and pickup coils. The driver coil produces a strong magnetic field that weakens as it penetrates to the pipe's outer wall. This now weak magnetic field produces small circulating eddy currents on the outer surface of the pipe. The eddy currents decay as they travel down the pipe, and fields produced by these eddy currents return through the pipe to the pickup coil. Any pits or cracks will alter the returning field, causing a change in the signal produced by the pickup coil. 


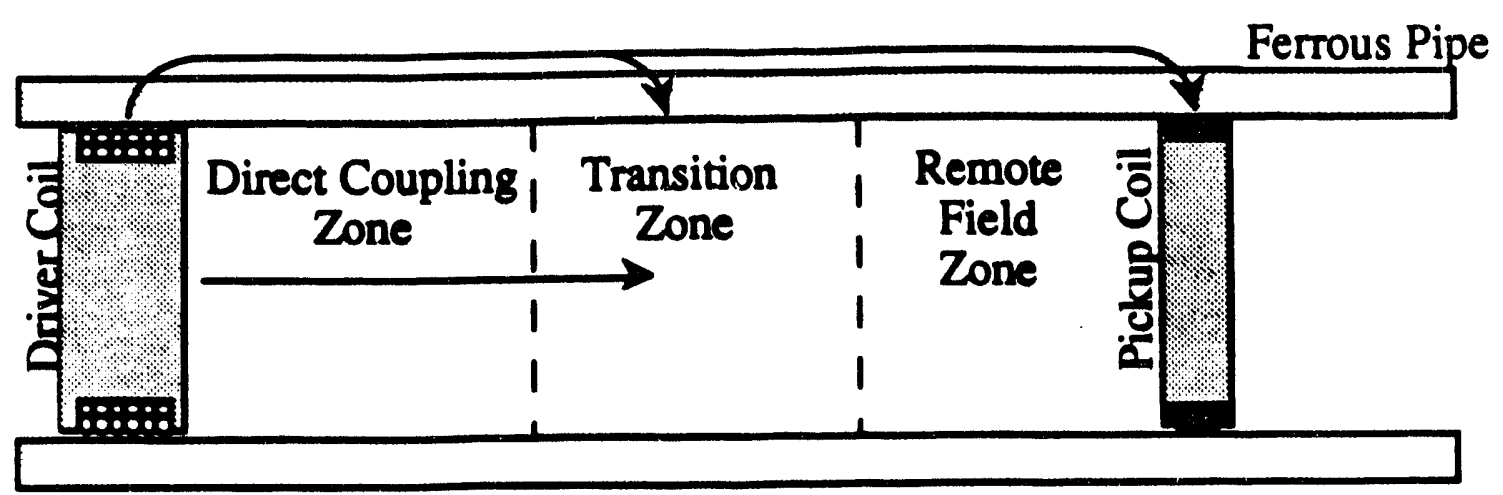

Fioure 12 - Remote fild addy cunent probe

\section{FrinRET eddy current coil design}

The RFEC probe forms the basis for the design used on the FWRRET, which uses a driver coil and four differential pair pickup coils. A 1.41 inch diameter Delrin ${ }^{\mathrm{TM}}$ bobbin forms the core of the driver coil, and an oval bobbin is used for the pickup coils. Figure 13 shows the pairing of the pickup coils in the RFEC probe to reduce the effects of signal noise.

As the probe moves down the pipe, it is impossible to maintain a constant distance between all the coils and the pipe wall. Lift-off is the term given to this varying distance between the probe and the pipe wall. By arranging the coils as a coil pair you can greatly reduce the effects of lift-off.

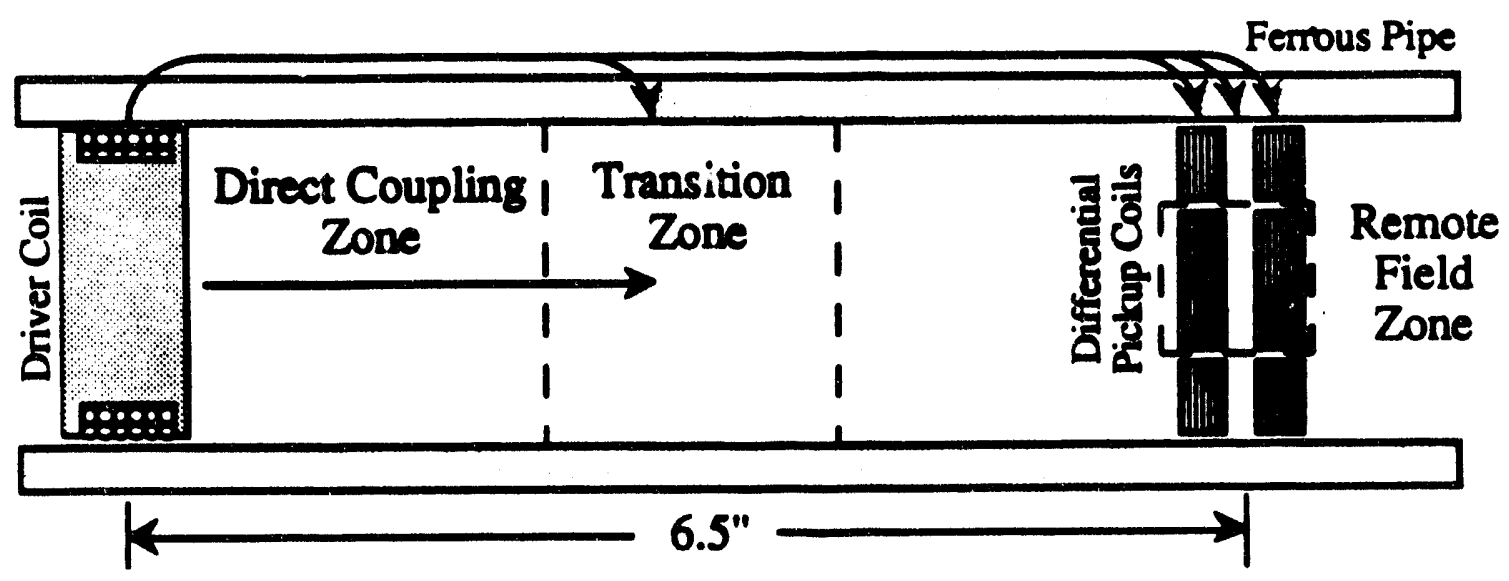

Figure is - RFEC probs with difforential palrs 
As the probe travels down the pipe toward a crack, the first pickup coil of the pair will sense a flaw before the second coil. At that moment, the coils are not seeing the same surface and the pickup coils will produce different signals. An amplifier highlights this difference to precisely locate the flaw.

\section{FHRRET's unique electronic design}

Typical eddy current probes receive their power and transmit their data over a large multi-conductor signal cable. However, due to the many elbows that are present in the waste tank cooling pipes, a single 38 gauge twisted pair signal wire is used. See figure 14 One thousand feet of the signal wire was spooled and placed in the rear of the FERRET. However, because this wire would not support the transmission of electrical power or high quality analog data, the FERRET needed its own power source and data processing capability.

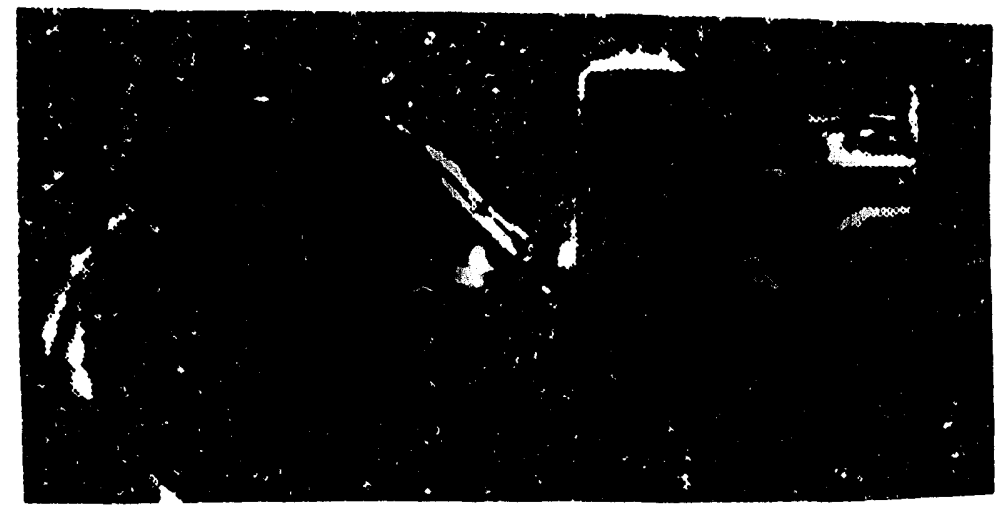

Figure 14 - 38 gauge twisted pair communications spool

A rechargable power source combining $20 \mathrm{NiCad}$ batteries was designed to generate enough power to operate FHRRET's electronics and power the driver coil for one hour. See Figure 15.

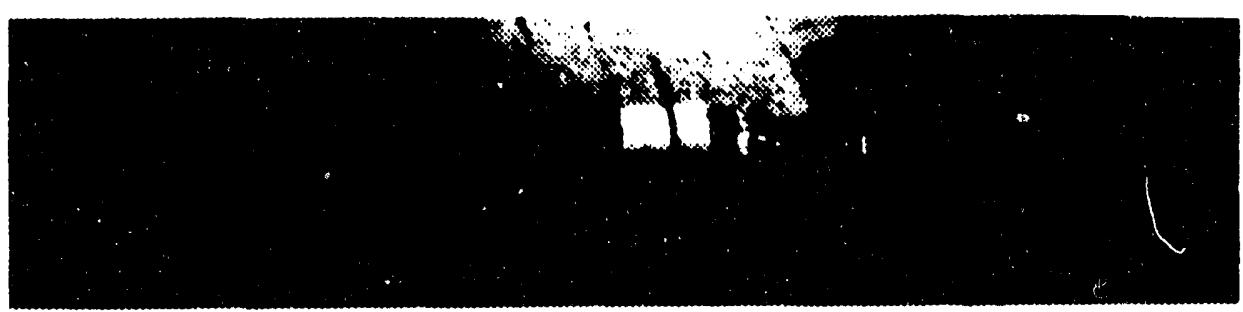

Floure 15 - 20 battery power pack 
FHRRET's onboard data processing outputs a signal that is unaffected by noise on the twisted wire pair, and does not require high speed data transmission. To achieve this capau. ity, a driver coil oscillator, communications circuitry and phase and amplitude detectors had to be designed. This difficult task was accomplished by breaking down the physical process into stages: formation of the electromagnetic wave, eddy current pickup, signal amplification, signal filtration, phase and amplitude detection, and transmission of the phase and amplitude data out of the carbon steel pipe.

\section{Communications designs}

So much data is generated by the FHRRWT sensors that the outputs of the circuits must be multiplexed to transmit the data through twisted-pair wire. This required the development of a multiplexer that could be added to the FERRET and a de-multiplexer at the end of the twisted-pair wire.

The original communications circuitry converted the data to a frequency representation. However, this design was not very stable during actual tests in the mock-up and consumed an enormous amount of power. This design was abandoned and replaced with a much simpler circuit in which one wire of the twisted pair is used as a ground reference.

After experimenting with the original communications designs, a new concept was developed to transmit digital data. The twisted wire pair had a greater bandwidth than originally assumed, allowing raw data to be digitized, thus negating the need for data analysis within the FMRRET and simplifying the design of the electronics. This new design, which precedes adoption of purely digital signal processing, has been successfully simulated in laboratory computers.

\section{Software Development}

Computers control all the positioning, data gathering, and analysis it this new cooling pipe testing process. An IBM ATTM, using LabWindows ${ }^{T M}$ software, commands the volume displacement pump to flush water through the cooling coil, and the FirRRE's position is calculated by the amount of water that has been pumped. An Apple Macintosh ${ }^{\mathrm{TM}}$ collects the data from the FWRRMT, and displays one channel in real time, storing the other channels on disk for future analysis. See Figure 16. The data collection and data analysis software was written in the LabView' ${ }^{\mathrm{TM}}$ environment. 


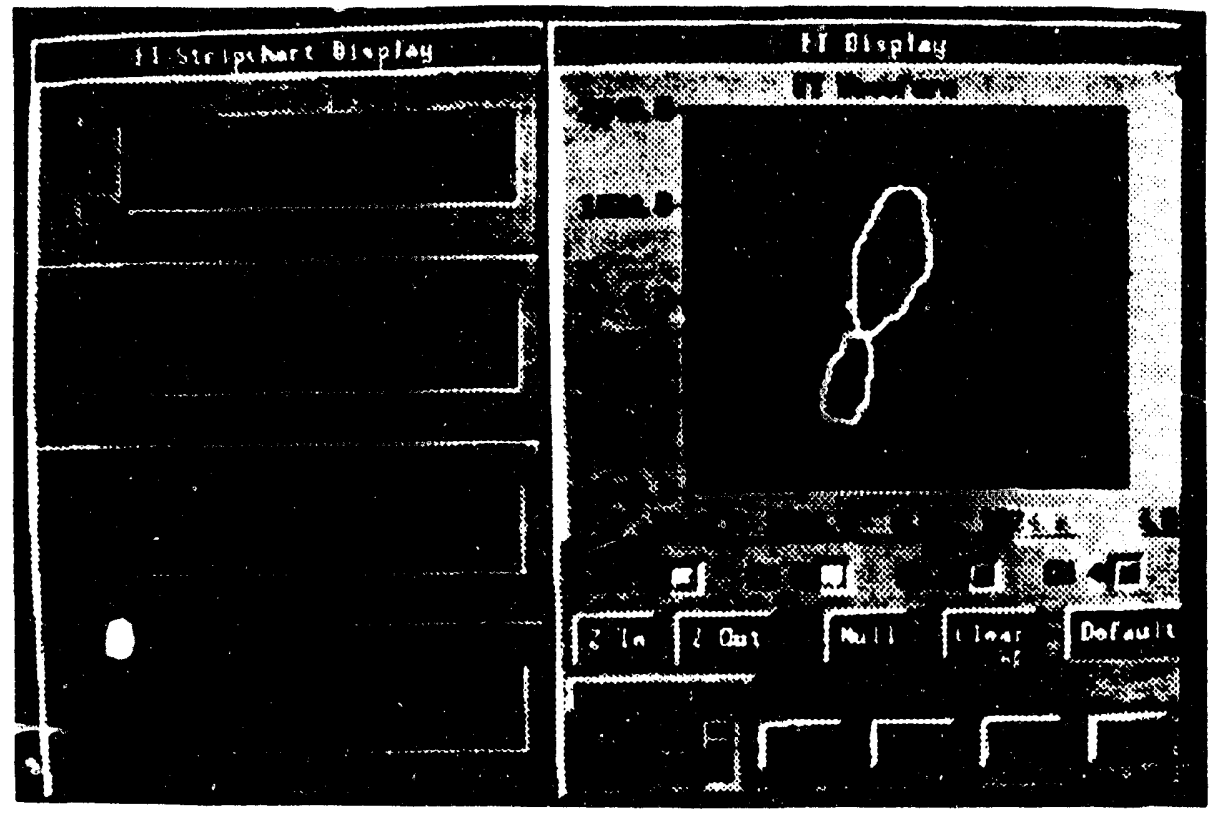

Figure 16 - Labl. ow data analysis soffware control window

\section{Pressure inspection technique}

Of the several tools written and tested in the LabView ${ }^{\mathrm{TM}}$ environment, the most useful can show all four channels of eddy current data simultaneously on an $X Y$ graph, plotting the pressure traces that are collected during a test to compensate for inaccuracies in the positioning data. In this manner a new reference point, based on the pressure spikes that occur when the FERRRET crosses a weld, can be established. While testing the launcher using commercial cleaning pigs, the detectors showed that pressure within the system would spike every time a weld was encountered, and increase as the pig traveled through elbows. By recording the pressure information on a strip chart, the location of every weld, elbow, curve, fitting, etc. could be seen.

Since the scale of the chart is known, the locations of all of the features within the cooling pipe can be accurately mapped, giving inspectors an unprecedented advantage when they evaluate the FERRET's data in detail. 


\section{FTRRET sniffs out leaks, too}

When it was suggested that this approach could be used to locate leaks in the piping, the large mock-up was modified by adding through-wall leaks, and a height-adjustable drain line was attached to simulate leaks at various fluid depths. Cleaning pigs were then pumped through the system at various speeds using the different sized leaks, and it was discovered that a leaking loop can be identified immediately by this method.

As the pig is moved towards the leak, the pump suction pressure is kept higher than normal by fluid drawn in through the leak. After the pig passes the leak, the suction pressure drops. The resulting slope in pressure can easily be seen on the strip chart, pinpointing the location of the leak within inches.

\section{FERRET - a continuing story of success}

Many waste tank inspection teams have dreamed of having FIRRST's advanced technology, but this invention is likely to have applications beyond the nuclear industry. Wherever access to piping is limited, remote field eddy current testing can disclose potentially dangerous contidions before the system plumbing actually fails. Think of how many ways this concept could work for you - then contact us for more information.

\section{Westinghouse Savannah River Company Equipment Engineering}
Alan Smoak W. Thor Zollinger
(803) 725-1106
(803) 725-3920 

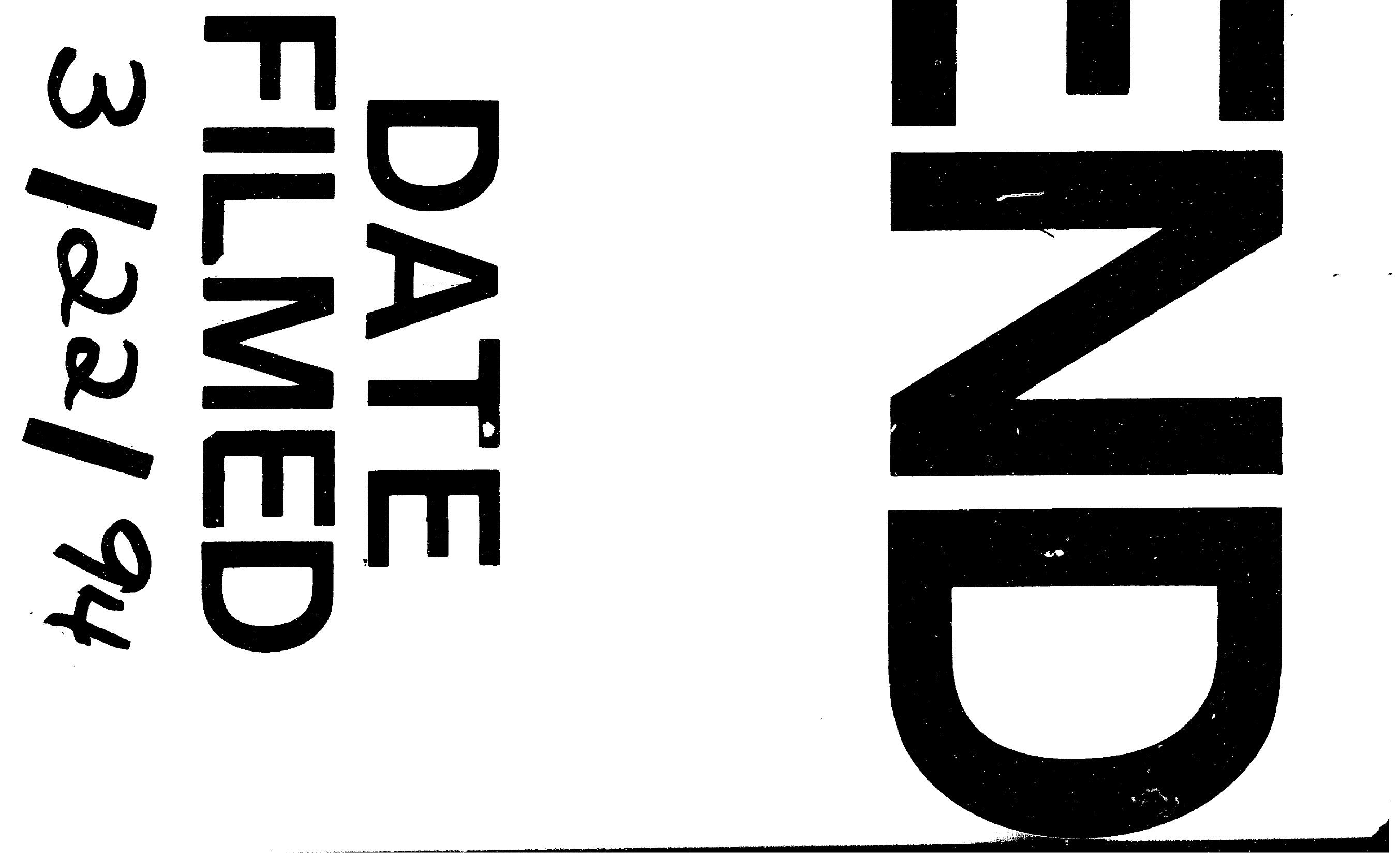
